occupy between the very sharp and bracing climate of the northern seaports and the relaxing ones of the extreme south, appears especially suitable to such cases; they exist generally in women of somewhat feeble tone, who require bracing and tonic treatment, but are, at the same time, incapable of bearing cold.

Before I conclude, let me touch upon a very important point ; im portant to all, but especially so to those who, like myself, practise in health-resorts. We are frequently appealed to for advice and counsel, both by patients and lodging-house keepers, when attending cases of a contagious nature. Sometimes the friends of the patient are anxious to hush up the nature of the illness in order to avoid expense and trouble; next, the lodying-house keeper is greatly tempted to join in the same petition ; for once let it be known that illness of a contagious character (such as scarlatina) has occurred in any house (whatever precautions may have been taken, however carefully the house and its inmates may have been disinfected) naturally that house is liable to be shunned for a time, perhaps for a whole season, and to some beginners, who have commenced on borrowed capital, this means beggary, or at the best a hard struggle for many years to repair the loss thus unwittingly and innocently incurred. The doctor is appealed to. Need I say that he has an obligation to his patient? True, but I hold that he has also an obligation to society, an obligation to mankind, to lessen disease, to prevent its spread as far as lies in his power; an obligation so binding, so imperative, that the lesser one becomes absorbed, almost lost, in the greater. I consider, therefore, that his duty is plain, to impress strongly on the householder that the other inmates should be at once informed of the nature of the illness, and that suitable precautions should be immediately adopted to limit, and prevent if possible, any further extension of the disease. I do not think it should be imperative on the medical attendant to inform the Sanitary Authority of the nature of the case; but I would make it compulsory on the householder (having been so informed by the medical attendant) in order that in all cases proper means of disinfection should be employed. Such precautions would go a long way towards stamping out some forms of zymotic disease, 1 do not say entirely, as cases will occur of so slight a character as to be indistinguishable, and which are yet focus points of fresh contagion.

Gentlemen, I bave now, in a very imperfect manner, passed in review the sanitary aspects of this place, the basis on which they rest, and the cases which can be most conveniently and best treated here. You will have observed that I omitted to mention a large class who come to the seaside to recruit an exhausted brain and enfeebled body; these luxuriate in that fresh air, change of scene, and quiet which are here afforded them, and return once more strengthened and nerved to that eager battle of life which we see going on all ar.sund us. In conclusion, I can only thank you most sincerely for the kindness with which you have listened to this address, and expreis the hope that, in view of the many attractions provided by the local com mittee, I have not already detained you too long.

\section{ON HIP-DISLOCATIONS.}

\section{By WALTER RIVINGTON, F.R.C.S.Eng., M.S.Lond.,} Surgeon to the London Hospital.

Probably it was a fortunate circumstance that, when Mr. Morris wrote his paper on "Dislocations of the Thigh", he was unaware that Professor Fabbri had anticipated the views with which his name will be associated; for if he had known that Fabbri had demonstrated some years ago at St. Bartholomew's Hospital the mode of occurrence and reduction of displacements of the head of the femur, he might have been induced, in the revulsion of feeling which is occasioned by the discovery that some inconvenient predecessor has stolen our best thoughts, to withhold his very valuable and (so far as he is concerned) original paper from the Royal Medical and Chirurgical Society, contenting himself with a less efficacious channel for the publication of his investigations. The result would have been that, notwithstanding the citations from Fabbri which Mr. Holmes has made in his work on the Principles and Practice of Surgery, a large proportion at least of the practical surgeons of the day would have known little or nothing of Fabbri, but still be quoting Bigelow as the ultimate authority on the subject.

A copious and careful paper like that which Mr. Morris brought before the Royal Medical and Chirurgical Society was greatly needed to elucidate the principles which underlie the manipulations commonly employed in the reduction of dislocations at the hip. We knew all about the ilio-femoral or $\mathbf{Y}$-ligament of Bigelo $\mathrm{N}$, and the questionable distinctions which he has drawn between dislocations above and dislocations below the obturator tend,n. We knew that flexion relaxed the $\mathbf{Y}$-ligament, and that in the subsequent movements of reduction the motion of the head of the femur was controlled by the tension of that ligament, but we did not know exictly the rationale of "abduction" and "rotation outwards", to use the terms according to their ordinary application; "abduction" for the movement of the shaft of the femur outwards from the middle line of the body, and "rotation outwards" for a movement round an axis drawn through the head and lower end of the femur. The latter movement some replace by one of circumduction, both the terms "rotation outwards" and "circumduction", and the movements themselves, being often loosely applied. With all our knowledge, however, it must be confessed that both teachers and students were rather hazy in their ideas of the meaning of each step in the process of reduction, as well as in regard to the part of the capsule which suffers rupture and the positions of the limb most favourable to displacement.

Our authorities teemed with Bigelow and were innocent of Fabbri. Bigelow was quoted with approval where his opinion was doubtful and his advice hazardous. His opinion that in certain cases difficu't of reduction the obstacle to reduction is the untorn capsule, and his directions for tearing the capsule further to facilitate reduction, have been adopted by eminent surgeons. A part from the probsble error of the opinion, it was by no means satisfactory to be inculcating freedom of manipulation upon students and house surgeons with the avowed object of rupturing untorn portions of the capsule. The scientific mind, sympathising with Hamlet's advice to the players, revolted from the idea of "sawing the air too much" with the patient's limb, and mindful of the not very remote danger of rupturing the sciatic nerve, preferred in the most obstinate cases to "use all gently and to beget a temperance which should give" the reduction "sm $)$ othness". Whilst we are encumbered by these difficulties and drawbacks, $M r$. Morris opportunely appears, and traversing independentiy the ground already occupied by the Italian professor, lays down certain definite and precise propositions which, if established beyond controversy, rem ove all haziness and obscurity from the subject. I say, if established beyond controversy; because one or two of Mr. Morris's propositions appear to me to be drawn in too rigid terms and to need some qualification. Having seen only the abstract of his paper in the journals, I am not in possession of the evidence on which he bases his conclusions, and cannot form an opinion as to the exact extent to which the evidence supports his canons ; but the impression produced on his audience, the observations of others, and my own experience, would lead me to concur in his propositions so far, at least, as to admit that he has correctly described one mode, and a frequent mode, in which dislocations of the head of the femur occur and the manipulations necessary for their reduction. As at present advised, however, I am not prepared to admit, without exception, his doctrines : $\mathbf{I}$. That all displizcements at the hip, without fracture, occur during abduction of the lim' ; 2. That the capsule is ruptured always at the lowest part; and 3. That there is one primary dislocation at the joint, all the other varieties baing secondary thereto.

I. Do all the displacements of the head of the femur occur during abduction? There is not the slightest doubt that on the cadiver it is comparatively easy, or rather comparatively less difficult, to produce dislocation by abducting the femur. On abduction, the ligaments $m$ ny be heard to crack at the outset of the manipulation ; on adduction, they do not yield until this movement is combined with rotation inwards, and even then displacement is not readily effected. Experimenting on a subject recently, I succeeded in effecting dislocation during adduction, but not until I had divided the muscles attached to the trochanter major. The head of the femur then escaped through the capsule posteriorly without rupture of the ligamentum teres. On the other hand, I was able, without interference with any structure, to dislocate both femora on to the dorsum during or subsequently to abduction by flexion and rotation inwards. The number of my trials is nut sufficient for dogmatic assertion, but enough to show that dislucation is more readily effected during or after abduction. On the other hand, I think it safe to conclude, that though greater force is requisite to effect displacement during adduction, there is really nothing absolutely to prevent displacement without fracture occurring whilst the limb is adducted. The greater strength of the capsule at the part where the head impin res during a lduction and the grea'er resistance of the muscles (especially during the continuance of rigor mortis) in this movement, make the dislccation difficult to the minipulator; but in the living subject, with relaxed miscles and exposure to force far superior to any which can be applied by an operator on the cadaver, what is there to hinder displacement during adduction? The conditions under which the femur is displaced in the living subject are scarcely compurable to those under which the stiff limb of the dead subject is manipulated. In getting out of a railway carriage a man falls on his side on the plat- 
form with his head towards the engine and one of his legs towards the carriages; the moving carriage pressing against his leg displaces his femur during flexion of the hip-joint. Would it matter in this case whether the limb were adducted or abducted? What would prevent displacement under such circumstances during adduction of the limb? (Lancel, 1872, vol. i, p. 10.) That displacements do occur during adduction has been the prevailing opinion of surgeons; and though they may have been mistaken as to the position most favourable to displacement, we can scarcely dismiss their observations as unworthy of consideration. During the discussion on Mr. Morris's paper, Mr. Maunder adduced the views of Malgaigne in favour of displacement during adduction. Taking down Dupuytren on "Diseases and Injuries of Bones", I find a case in point at page 369 : "Dislocation of the Left Thigh reduced after a lapse of thirty-one days. -Pierre Guilleminot, aged 2I, a labourer of spare habit, whilst wrestling with a companion, was thrown on his left side, the corresponding leg and thigh being carried forwards and strongly adducted" (the italics are mine) "so as to cross the leg and thigh of the opposite side. The left femur was thus placed obliquely between the body and the ground; the outer side of the lower part resting on the ground, and the upper part supporting the weight of the body ; and by the leverage thus obtained the head of the bone was dislocated upwards and backwards." Are we recklessly to throw such a case overboard because it does not fit in with our cadaveric manipulations? I trow not.

2. Is the capsule always ruptured at the lower part opposite the thyroid notch? Mr. Holmes, in speaking of dislocations produced on the dead subject, says, "In all forms of dislocation the capsule is freely torn away, though to a variable degree, from the rest of the acetabulum, but the upper and outer part of the capsule and the ilio-femoral ligament representing the two branches of Bigelow's $Y$-ligament remain untorn". (Op. cit., p. 184.) Mr. Callender tells us that "the violence which causes the dislocation and which forces the bone through the capsular ligament ensures also that the latter should be torn to pieces". (Lancet, 1868, vol. i, p. 343.) Sir Astley Cooper found in a dissection of a dislocation on the dorsum ilii that the "orbicular" (by which, I presume, he meant the capsular) "ligament was entire at the superior and anterior part only, and it was irregularly lacerated throughout the remainder of its extent". (Treatise on Dislocations and Fractures, p. 60.) In dissecting a dislocation on the pubes, he found the capsular ligament extensively lacerated. Mr. Syme found the capsular ligament extensively torn close to the edge of the acetabulum in dissecting a dislocation into the sciatic notch. Hamilton says "that in some cases the capsule being completely, or almost completely, torn away, the muscles offer the only resistance". On the dead subject, I found that by manipulations not very powerful, which effected the dorsal displacement, I had torn away the capsule from the margin of the acetabulum for more than half its circumference, and had ruptured the obturator internus gemelli pyriformis and smaller glutæi. The subject was a man advanced in years. These observations appear to be sufficient to show that it is unsafe to indulge in too rigid generalisations on conditions which admit of considerable variety, and that it must be quite impossible to localise rupture of the capsule to one small part in all cases. At the same time, I quite think that where the capsule is torn only to a limited extent, the seat of the rupture will be in the weak region indicated by Mr. Morris, although it is not clear that he is absolutely correct in affirming that the rent will be at the lowest point of the acetabulum below the head of the bone. My colleague Mr. McCarthy has reported in the Lancet of 1874 two cases of dissection of dorsal dislocation, and he found the rent posteriorly in each case. "The most posterior part" of the capsule are the words used in describing the position of the rent in the second case, which was uncomplicated with fracture.

3. The third proposition of Mr. Morrisis, that there is only one primary displacement downwards, and that the varieties of hip-dislocation are secondary thereto. If the capsule can be so freely lacerated behind, it is not necessary for the head of the bone to descend before it ascends on to the dorsum or passes back to the sciatic notch or some neighbouring position. Cases occur, in which it is difficult to reduce the dislocation by manipulation, but which yield readily to extension. Such a case occurred in my own practice at the London Hospital. The displacement was backwards, the so-called sciatic displacement. The patient was put under chloroform, and I tried manipulation as recommended by Mr. Morris, and failed. Mr. Hutchinson and Mr. Couper each took a turn with the same result. I then applied a jack-towel to the limb, placed my bootless foot in the perinæum, and slipping the towel over my head and shoulders made steady traction. Reduction was speedily effected. It is possible that part of the rim of the acetabulum was injured, but that would not have prevented the success of manipulation. Most likely the rent was behind, and in our manipu- lations we brought the head too low or opposite the spot indicated by Mr. Morris, and therefore failed to effect reduction.

Before demurring to Mr. Morris's conclusions, I should have preferred to see his paper, for possibly he may have anticipated the points which I have raised, and explained them in such a manner that they may support rather than invalidate his views; but inasmuch as the discussion on his valuable paper has been extended beyond the area of the Royal Medical and Chirurgical Society, and Mr. Morris is engaged in strengthening his position, I think it as well to put before him the points which have occurred to me, and may occur to others, after reading the abstract of his paper, and comparing his views with their knowledge and experience of the dislocations which he has done so much to elucidate. These points I will put in the form of propositions.

1. On the dead body dislocation of the head of the femur may be effected with comparative facility during or after abduction, but with difficulty during adduction of the limb.

2. There is nothing absolutely to prevent dislocation of the head of the thigh-bone from occurring in the living subject during adduction of the limb.

3. Experiments on the dead subject cannot be made the complete test of the mode of occurrence of dislocations in the living subject.

4. In the living subject the capsule is often lacerated at once so freely that the head of the bone can escape either downwards, backwards, or backwards and upwards ; and, therefore,

5. There is no reason why the head of the bone should pass primarily downwards before reaching the dorsum or the sciatic notch.

6. In the living subject, the capsule seems to be ruptured as frequently behind as below.

\section{CASE OF OVARIOTOMY PERFORMED UNDER SPRAY : PEDICLE TIED IN SECTIONS WITH ANTISEPTIC LIGATURES.}

By G E O R G E. Y. H E A T H, M. D.,
Senior Surgeon to the Newcastle-upon-Tyne Infirmary.

Ovariotomy is now so frequently performed, and is so often successful, that I have not hitherto thought it worth while to place any case on record ; but, as the present operation was done after the antiseptic method, which, I believe, is not generally adopted in ovario tomy, and the result has been more than usually successful, I think a short account of the case may be sufficiently interesting to justify its publication.

The patient, Mrs. K., aged 54, married but not a mother, was a tall thin person, who for several years had suffered from an ovarian tumour. On February 23rd, the girth round the belly measured forty. eight inches. She was then tapped, and forty-two pints of viscid liquid withdrawn. After the tapping, the swelling entirely disappeared, with the exception of a hard mass as large as a cricket-ball, firmly fixed at the right hypochondrium. The cyst rapidly refilled, and, on April I 4 th, the patient's size was nearly as large as before the tapping. I considered the case a favourable one for the radical proceeding. After consultation with Dr. Bourne, and the patient being desirous of undergoing the operation and sanguine of recovery, ovariotomy was done on that day in the following manner.

The temperature of the bedroom having been raised to 60 deg., the patient was placed upon a table, and anæsthesia produced by chloroform and kept up by ether. The administration of these agents was undertaken by Dr. Hope, and carried out in his usual careful and efficient manner.

I was assisted by Dr. Bourne of North Shields, the patient's usual adviser ; by my friend Dr. Barron, and by Mr. Williamson, the senior house-surgeon of the Infirmary. A steam-spray was placed upon a raised platform in front of, and about four feet from, the patient's belly, so that the finer particles of the spray only should fall upon the wound. The skin of the abdomen was washed with the one to forty solution of carbolic acid, in which the instruments and sponges to be used, as well as the hands of those engaged in the operation, were immersed. Towels wrung out of the same solution were placed beneath the patient and over the lower part of the belly and the vulva. Antiseptic guards of new flannel were also provided, to be used in the way hereafter mentioned.

The incision, of medium size, was made in the usual way, and, the cyst having been exposed, a small opening was made in it before commencing its separation from the peritoneum, and about a third of the contents allowed to escape. The cannula was then introduced, and the sides of the opening held firmly around. The hand was next passed between the cyst and the peritoneum. Extensive adhesions 